\title{
Ouvir o documentário: vozes, música, ruídos
}

\author{
Gabriela Machado Ramos de Almeida*
}

Maia, G. \& Serafim, J.F. (Orgs.) (2015).

Ouvir o documentário: vozes, música, ruídos. Salvador: EDUFBA. ISSN 97885-232-1419-7.

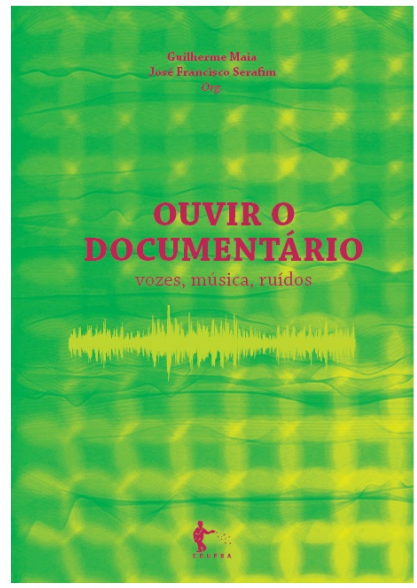

A fortuna crítica em torno do som no cinema ganhou corpo no Brasil especialmente nos últimos dez anos, impulsionada sobretudo pela criação do Seminário Temático de Estudos do Som, na SOCINE (atualmente intitulado Teoria e Estética do Som no Audiovisual) e pela publicação de artigos em períodos da área de Comunicação. O interesse pelo tema é crescente e se reflete na quantidade e na relevância do que tem sido produzido em nível teórico. ${ }^{1}$

Apesar deste crescimento, o convite a ouvir o cinema, de forma ampla, se mantém bastante desafiador, quando comparamos o volume de estudos sobre o som nos filmes às contribuições relativas a outros dos seus aspectos estéticos e de linguagem (como mise-en-scène, dramaturgia, montagem ou construção plástica). Ouvir especificamente o documentário, então, parece ainda mais instigante, já que as referências sobre o assunto permanecem escassas.

* Universidade Luterana do Brasil - ULBRA, Curso de Comunicação Social, habilitações em Jornalismo e Produção Audiovisual. 92425-900, Canoas, RS, Brasil. Email: gabriela.mralmeida@gmail.com

1. No entanto, é necessário pontuar que seguem inéditas no Brasil obras consideradas fundamentais, de autores como Michel Chion, Claudia Gorbman e Russell Lack. 
O livro Ouvir o documentário: vozes, música, ruídos, organizado pelos professores Guilherme Maia e José Francisco Serafim, do Programa de PósGraduação em Comunicação e Cultura Contemporâneas da UFBA, responde a esta provocação. A coletânea é oriunda de um seminário internacional homônimo, realizado em novembro de 2012 na Universidade Federal da Bahia, em Salvador, e na Universidade Federal do Recôncavo da Bahia, em Cachoeira. Assim, alguns dos artigos integrantes da obra são desdobramentos de trabalhos apresentados no seminário e outros são contribuições de autores que foram convidados a participar do livro, que tem como objetivo suprir uma lacuna nos estudos sobre o documentário e considerá-los em sua dimensão sonora, esteja ela manifestada na música, nas vozes ou nos ruídos, como o título sugere.

O livro se articula em torno de três grandes temas: o som nos documentários de teor antropológico ou etnográfico; a música e a canção no documentário brasileiro e a voz. Como uma espécie de preâmbulo à discussão levantada pelos artigos, um texto de Bill Nichols, que esteve presente no seminário como conferencista, abre a coletânea. Com uma abordagem historiográfica, este primeiro capítulo, intitulado $O$ filme documentário e a chegada do som, trata da introdução do som na década de 1930 e seu impacto no documentário, especialmente na constituição do modelo expositivo baseado na "voz de Deus", a voz de uma autoridade que detém o saber.

O comentário falado aparece como uma costura que dá forma a um conjunto de materiais recolhidos do real e organizados segundo uma perspectiva que, naquele momento (e em grande medida até o presente), busca prioritariamente um efeito de convencimento do espectador e de controle do discurso. Nos anos de 1960, década considerada um ponto de virada na ética e na estética do documentário em função da popularização de câmeras leves e portáveis mas, principalmente, dos gravadores que permitiam a gravação do som sincronizado, a dimensão sonora dos filmes adquire novos contornos, priorizando o registro dos sons ambientes e das falas dos indivíduos filmados, de modo que ganha protagonismo não mais a voz da autoridade caraterística do documentário expositivo clássico, mas as vozes das pessoas que surgem nas imagens.

O segundo capítulo, de autoria de Marcius Freire (UNICAMP) e intitulado A escuta do comentário no filme antropológico, dá continuidade à discussão iniciada por Nichols, tratando especificamente da centralidade do comentário no filme antropológico, a partir das contribuições de Claudine de France em torno da mise-en-scène das imagens e da mise-en-scène do comentário. Freire sublinha a importância de considerar o comentário como uma ferramenta que ajuda a juntar os fragmentos de que se compõe o documentário para criar um discurso sobre o mundo histórico de acordo com as intenções do realizador. 
Para abordar o que chama de mise-en-scène do verbal, o autor recorre a três processos autônomos e complementares que normalmente articulam os filmes: o comentário elaborado pelo realizador antes (como um roteiro ou esboço prévio à tomada), durante (em entrevistas, por exemplo) ou depois de filmar (na pós-produção).

No terceiro capítulo, Breves considerações acerca dos sons no filme etnográfico, Joceny de Deus Pinheiro (UNILAB) parte da constatação de que o som é negligenciado nos estudos sobre este tipo de obra e da hipóteses de que, se captados e tratados de forma competente, os sons não verbais contribuem para aumentar a "densidade etnográfica dos processos abordados" e para atribuir à fruição dos filmes uma dimensão mais sensorial. Baseando-se em Paul Henley, a autora fala de uma inaudibilidade do som não verbal e de uma "ditadura do olhar" marcantes na antropologia visual, que atestam uma hierarquia entre imagem e som e uma preponderância da imagem no filme etnográfico (latente no próprio fato de que se costuma chamar a antropologia baseada no instrumental cinematográfico de visual, e não de audiovisual).

O quarto capítulo, A invenção da etnoficção em Jaguar de Jean Rouch: uma análise da mise-en-scène do comentário, Sandra Straccialano Coelho (UFBA), dá sequência à investigação do som no filme etnográfico a partir da observação de parte da produção do cineasta francês situada na década de 1950. Para analisar Jaguar, filmado em 1954 e concluído apenas em 1967, Coelho se baseia nas noções de autocomentário (aquele feito pelo sujeito filmado), de etnoficção (que designa, na antropologia fílmica, obras que misturam aspectos documentais e ficcionais e tem em Rouch um seus principais expoentes) e na mise-en-scène do comentário proposta por France e convocada também por Freire em seu artigo. Numa experiência precursora da estratégia de utilizar o autocomentário e a improvisação na etnoficção - anterior mesmo a um dos seus filmes mais famosos, Eu, um negro - Rouch reinventou o filme etnográfico e tensionou os limites entre documentário e ficção, como nos informa a autora.

$\mathrm{O}$ artigo seguinte, quinto capítulo do livro, $O$ documentário como tomada da palavra: reflexões sobre a mise-en-scène da fala e os dispositivos documentais, de Amaranta Cesar (UFRB), aborda a obra do cineasta canadense Pierre Perrault a partir do conceito de "tomada da palavra", elaborado por Michel de Certeau, que diz respeito à conquista do poder de fala que permite a uma comunidade minoritária fundar ou refundar uma identidade cultural própria. Cesar contextualiza o início da produção de Perrault na década de 1960 e a sua importância como cineasta atuante às margens do Cinema Direto e do Cinema Verdade. Em seguida, busca estabelecer uma aproximação entre 
o primeiro documentário de longa-metragem do cineasta, Para que o mundo prossiga (1963) e o documentário brasileiro Terra deu, terra come, de Rodrigo Siqueira (2010), tomando este último como um exemplar contemporâneo de exploração da mise-en-scène da fala com um sentido ao mesmo tempo político e estético, como em Perrault.

O sexto capítulo, escrito por Guilherme Maia (UFBA), é intitulado Um cabra marcado pelas canções: ensaio sobre a poética musical dos documentários de Eduardo Coutinho e dá início à segunda grande seção temática do livro, dedicada à música e à canção no documentário brasileiro. Maia apresenta a hipótese de que o uso da música por Coutinho foi sendo construído e modificado ao longo de suas obras, passando por momentos de uso mais convencional, por outros de ausência quase total e chegando, por fim, num estágio em que o cineasta praticamente abandona a música composta para os filmes e passa a apostar prioritariamente em canções populares. Boa parte delas é interpretada pelos próprios personagens dos documentários, como ocorre em Boca de Lixo (1992), Edifício Master (2002) e, posteriormente, de forma mais incisiva em As Canções (2011), um filme inteiramente dedicado à importância da canção para o universo afetivo das pessoas. Para Maia, esta trajetória consolida efeitos de natureza emocional no espectador pretendidos por Coutinho a partir do momento em que ele seleciona como personagens não apenas "pessoas que cantam, mas pessoas que cantam bem", no sentido de que expressam emoção e sentimento por meio do corpo, das palavras e da melodia.

Márcia Carvalho (FAPCOM), no sétimo capítulo do livro, A biografia cantada de A música segundo Tom Jobim, aborda a biografia no documentário e se dedica à análise de um filme pouco convencional no seio da produção audiovisual centrada em personagens da música. A música segundo Tom Jobim (2012) se apresenta como uma colagem de vídeos e fotografias que se alternam entre o próprio Tom Jobim em diferentes momentos da sua trajetória e diversos artistas e grupos musicais interpretando suas canções, num seleção bastante abrangente em que cabem desde Elizabeth Cardoso e Elis Regina até Fernanda Takai, Carlinhos Brown e Diana Krall. Não há entrevistas, narração ou organização cronológica, mas sim uma colagem de performances musicais. O filme, dirigido por Nelson Pereira dos Santos e Dora Jobim, permite que Carvalho questione o lugar da fala e da narração no documentário biográfico, o valor do arquivo para o documentário e os meios a serem empregados para recontar a história de um músico através do suporte audiovisual.

$\mathrm{O}$ oitavo capítulo, $O$ documentário indireto de Vladimir Carvalho em $O$ país de São Saruê, é escrito por Sergio Puccini (UFJF) e analisa o filme em questão partindo de uma definição criada pelo próprio cineasta para se referir 
ao tratamento sonoro da sua obra: som indireto. Como nos informa Puccini, trata-se da faixa sonora oriunda de um registro feito de forma precária. Neste caso específico, como não dispunha de equipamento para gravação de som sincronizado, Carvalho entrevistava alguns dos personagens filmados no final do dia, ao invés de registrar o som no momento da tomada "original". Para além de uma limitação imposta pelas condições de produção que impede a sincronia, Puccini afirma que o cineasta investe na valorização das vozes e na exploração de contraposições entre imagem e som.

No nono capítulo, Sensação e sentimento: o som do Rap do Pequeno Príncipe contra as Almas Sebosas, a autora Ana Rosa Marques (UFRB) aborda a música em um documentário que foge a um uso mais convencional do som, em dissonância com uma certa tradição do documentário que atribui maior valor de verdade aos filmes cujo extrato sonoro praticamente se restringe àquilo que foi registrado na tomada documental. Marques se refere a Rap do Pequeno Príncipe contra as Almas Sebosas (2000), como um filme que assume uma exploração dos sons como recurso narrativo e estilístico, seja na inserção de ruídos na pós-produção e na montagem que interfere nas falas dos personagens, ou ainda no destaque dado à música, que "gera ritmo e sentimento, provoca emoções, cria atmosfera, sintetiza informações e tece elos", segundo a autora.

O décimo capítulo, As vozes de Chris Marker, abre uma seção do livro dedicada à voz. Neste artigo, José Francisco Serafim (UFBA) aborda a importância do comentário oral e escrito na obra do cineasta francês, para quem o comentário nunca surge como ferramenta para explicar ou "subjugar" a imagem ao domínio da palavra (bem como a imagem igualmente não aparece para apenas ilustrar aquilo que diz o texto, seja ele falado ou escrito). Serafim categoriza três tipos de comentários e tece a sua análise sobre filmes de Marker que materializam cada um deles: o comentário epistolar em Carta da Sibéria (1958); o comentário dialógico em O mistério Koumiko (1965) e o comentário dialogado em Se eu tivesse quatro dromedários (1966).

O décimo primeiro e penúltimo capítulo do livro, Estratégias de aproximação: as vozes de Agnès Varda no documentário Os catadores e eu, de Tatiana Levin (UFBA), parte do conceito de voz do documentário em Bill Nichols e das contribuições de Michel Chion no livro La voz en el cine ${ }^{2}$ para analisar a voz subjetiva de Varda, dotada de um tom ensaístico e de um desejo por interagir com o mundo, mais do que de dizer-se objetiva ou imparcial. Conforme Levin, a cineasta se constrói no filme como uma "personagem-catadora-cineasta"

2. Edição espanhola consultada pela autora (2004). Referência original: CHION, Michel (1982), La voix au cinema, Paris: Editions de l'Etoile/Cahiers du Cinéma. 
que adota um ponto de vista bastante pessoal, se articula ao redor de uma "vozeu" e assume o gesto de catar de forma tanto literal quanto - principalmente metafórica.

Por fim, encerra a coletânea o artigo $O$ uso do som em falsos documentários de horror, de Rodrigo Carreiro (UPFE), que trata dos filmes de horror found footage, subgênero do cinema de horror em que obras de ficção adotam estratégias comumente associadas ao documentário, como o uso de registros com aparência amadora codificados como material de arquivo e que os filmes tentam, em grande medida, atestar como imagens "verdadeiras", colhidas no real. Carreiro se propõe a dedicar atenção especial ao som destes filmes, que compõem o corpus de uma pesquisa em andamento, visando identificar padrões em alguns aspectos como o uso da música, da voz e dos ruídos; as características do desenho de som e as estratégias de captação sonora. O autor apresenta alguns dados já consolidados em função da pesquisa empírica e afirma que os padrões e recorrências que foram identificados têm relação com a natureza dos próprios filmes em função do conflito entre legibilidade e verossimilhança (uma vez que o efeito final buscado é de registro do real, de documentários sobre eventos extraordinários ou sobrenaturais).

Apresentado o conteúdo do livro é possível afirmar que, do mesmo modo como é incomum a análise de documentários no contexto dos estudos do som no cinema, também são raras as investigações sobre o som na pesquisa em documentário, uma vez que seu estudo costuma se centrar em algumas chaves como ética, modos de representação, objetividade e subjetividade, dispositivos de criação e encenação. Se, por um lado, estas chaves dão conta de um conjunto de questões desde sempre muito caras ao chamado "cinema do real", por outro também quase que desconsideram a dimensão sonora dos filmes, com exceção dos que contam com narração (nestes casos, entretanto, os trabalhos costumam se centrar nos conteúdos da narração e não na sua operação narrativa ou estilística no filme). Ouvir o documentário: vozes, música, ruídos se apresenta como contribuição a dois campos de estudos de uma só vez, o do som e o do documentário, o que indica a pertinência dessa obra. 